\title{
Trust and Distrust in Two-sided Markets: An Example in the Sharing Economy
}

\author{
Christoph Mittendorf \\ Goethe University Frankfurt \\ mittendorf@wiwi.uni-frankfurt.de
}

\begin{abstract}
Mobile applications and Internet-based platforms continuously foster the rise of the sharing economy business model that can nowadays be found in various industries. In this paper, we focus on potential customers in the ridesharing industry. We use the setting of 'BlaBlaCar', a popular ridesharing platform, to investigate the implications of 'trust' and 'distrust' on the users' intention to engage in a sharing encounter. In particular, we extend the research model by Mittendorf (2017) which investigates the influence of trust and risk in the sharing economy. In this regard, we differentiate between the platform and the sharing partners, while incorporating both trust and distrust. Our study employs survey data $(n=238)$ and structural equation modeling (PLS-SEM). Our results provide empirical evidence that trust and distrust have unequal effects on the respective user intention, which contributes to the understanding of two-sided market platforms. Academic and practical implications are discussed.
\end{abstract}

\section{Introduction}

The popularity of two-sided online platforms has increased over the last years $[9,12]$. Contemporary sharing economy platforms make use of the two-sided market model to provide distinct services to potential customers, such as hospitality and transportation services [42]. The popularity of these new platforms (especially among young individuals [2]) has several reasons. First, modern sharing economy platforms claim to be more economic, environmentally friendly, and often include a social component, e.g. connecting two people on short notice [42]. Second, current sharing economy platforms are often based on new technologies like mobile applications and responsive web interfaces, which makes them easily accessible and provides a high usability that further facilitates the rise of the sharing economy [22]. In other words, today's modern information and communications technologies enable people to disintermediate traditional commercial channels and to share excess capacity with each other effectively $[1,4]$.

Various studies and current research claim that trust is the 'currency' of the sharing economy [5]. This statement seems inevitable and has previously conceptualized in related research streams, such as in the collaborative environment, where trust has been identified as an important influential factor [43], or in the ecommerce industry, where trust is stated to be a key component that influences the customers' intentions to transact $[29,48]$. Regarding sharing economy literature, researchers [24,41] lately found that trust in the platforms is one of the main drivers why people engage in service encounters - in the following, we refer to service encounters in the sharing economy as "sharing encounters"; hence people do not engage in selling or commercial renting practices. Most of the current sharing economy research relies on trust (respectively the lack of trust [57]) towards the platform or the corresponding sharing partners $[31,40]$ rather than including the concept of distrust despite the findings of McKnight and Choudhury (2006) who argue that distrust is an additional factor that influences the users' intentions in the online environment and therefore fosters the understanding of user behavior.

In this regard, a comparative examination of trust and distrust in two-sided sharing markets remains an open question [38]. Answering this question is the first objective of our study. Therefore, we analyze the implications of both trust and distrust on the customers' intentions to engage in a sharing encounter on the ridesharing platform BlaBlaCar. Moreover, as is already common in two-sided market research, we separate intermediary and users form each other and evaluate the distinct influence of trust and distrust of both entities on the customers' intention. We intentionally chose BlaBlaCar (a long-distance ridesharing platform) as a suitable setting for our analysis to study the influence of trust and distrust on modern sharing economy platforms, as the platforms uses current technology to connect strangers on short- 
term notice over the Internet. In our paper, we answer the following research question:

RQ: How does trust and distrust influence the customers' intentions on long-distance ridesharing platforms?

For our research, we adopted the research model of Mittendorf (2017), which investigates the building and implications of trust and risk on the sharing economy platform Uber. In addition, we follow the theory of 'Trust and Power' by Luhmann (1979), which comprises the fundamental conditions of trust and distrust as a functional equivalent and extension of trust. In this regard, we derive its validity from the sharing economy and propose a modified research model that seeks to explain the participation behavior in the ridesharing industry. By doing so, we contribute to the field of IS by complementing the theory of trustbased respectively distrust-based decision-making on contemporary sharing economy platforms. We expect that both trust and distrust influence the customers' intentions to engage on the respective sharing economy platform.

The remainder of this paper is structured as follows. In Section 2, we present the related work on the sharing economy, including the relevant literature on trust and distrust. In Section 3, we present the modified research model of Mittendorf (2017) and introduce our research hypotheses. In Section 4, we demonstrate our research methodology and present the survey results. We conclude our paper by discussing the implications of our findings, limitations, and directions for future research.

\section{Related work}

\subsection{The sharing economy}

Contemporary sharing practices supplant incumbent services in certain industries, such as in the hospitality [54,58] and the transportation industry $[1,7]$, while addressing the needs of new customers especially the younger generations through modern technology. $[4,9]$. In other words, sharing practices are on the rise as they realize economic, cultural, and organizational benefits and continuously outperform traditional ownership practices. which merely focus on obsolete commercial channels [22]

In this paper, we focus on the sharing economy a two-sided market model that can nowadays be found in numerous industries. For the purpose of this paper, we do not enter the discourse regarding the terminology, such as collaborative consumption, commercial sharing, or access-based consumption $[4,5,13]$. Instead, we focus on BlaBlaCar that enables its user to offer and request rides. In particular, our research focus concentrates on two-sided online market platforms that allows users to share private resources in the form of temporary access to goods and services without transferring ownership. To this end, BlaBlaCar focusses on long-distance ridesharing and connects drivers and passengers who are willing to travel together to a particular destination while sharing the cost of the transportation activity. Therefore, BlaBlaCar is different to Uber that mostly focusses on short-distance respectively short-duration ridesharing. An adequate trust basis seems necessary to establish a ridesharing engagement between its potential users.

\subsection{Trust and distrust}

Trust is a complex concept that has been studied in several disciplinary fields $[37,56]$. In the following, we assess trust as an attribute that originates through relationships among different entities [35,36]. Researchers have shown that trust is decisive in commercial and personal relationships [37,43] that involve interdependencies, risk, or uncertainties [26,56]. Hence, trust involves vulnerability [56]. The need for trust is particularly high in socially distant relationships, such as in the online environment, due to an increasing transaction complexity [29]. Hence, online interactions that cannot be fully controlled by the individuals require an adequate trust basis to function successfully [59]. Trust eliminates negative outcome possibilities from a consideration set [36]; thus, trust is claimed to be one of the most effective complexity-reduction mechanisms [8]. In particular, the need for trust increases with the rising dependency on other entities and growing vulnerability to their misconduct $[11,36]$. Researchers argue that trust plays a key role especially in the online environment respectively has been repeatedly identified as one of the most formidable barriers of people engaging in ecommerce [39,47,56], crowdsourcing [59], virtual teams [28], or the sharing economy [23,40,41].

In this regard, previous research shows mixed results on the implications of trust in intermediary frameworks, e.g. when referring to the findings of Mittendorf, $(2016,2017)$ in the sharing economy or Hong and Cho (2011), Kim, et al. (2008) in ecommerce. Hence, existing theory has difficulty to predict the implications of trust as a standalone construct in modern intermediary frameworks. Whereas trust has been studied thoroughly, there is scarce literature on distrust in IS literature, although various trust theorists agree that trust and distrust are separate constructs that have unequal effects. For 
example, Lee and Huynh (2005) found that trust and distrust are discriminant and have different outcomes.

Whereas, there are some researches that see only little empirical evidence that trust and distrust are distinct concepts, other researchers argue that a trustdistrust distinction can add explanatory power to a research model especially when relationships are multifaceted or multiplex [38]. In other words, distrust is a functional equivalent of trust and needs to be empirically validated together with trust in order to conclude trust relationships in an intermediary framework [36].

We believe that the combination of peculiarities of BlaBlaCar, such as shared rides on short notice between private individuals, the usage of Internettechnology, (non)transparency of certain demographic data and car information, interactions with strangers, and the intermediary framework, have an extensive effect on the implications of trust and distrust $[6,30,41]$. The mixed results in current literature, together with the peculiarities in our sharing economy setup, encouraged us to review the implications of trust and distrust for temporal ridesharing activities in the sharing economy.

\section{Hypothesis development and research model}

In order to close the formulated research gap, we introduce a research model that allows us to analyze the impact of trust and distrust on the users' intention to engage in a long-distance sharing encounter. In particular, our research model is based on Mittendorf (2017), who first introduced a research model to analyze trust and risk in two-sided markets respectively the sharing economy. We take the perspective of a customer respectively a potential passenger on BlaBlaCar. Ridesharing activities on BlaBlaCar are generally defined as interactions with strangers that imply high levels of complexity and risk [5,54]. In this paper, we apply the complexity-reduction mechanisms suggested by Luhmann (1979) and the findings of Mittendorf (2017). However, we go a step further and introduce the concept of distrust to advance our understanding of the respective relationships in the ridesharing industry; thus, increasing the explanation power with regard to the users' intention.

As is already common for research in two-sided markets [23,41], we separate platform and corresponding users from each other. Based on this, we assess the implications of two trust and two distrust constructs on the customers' intentions to engage in a sharing encounter. In this specific context, to engage in a sharing encounter can imply using the BlaBlaCar app to search for favorable drivers based on individual preferences respectively reviewing the drivers, including their name, photo, availability, and rating, as well as requesting a ride to receive a transportation service to a specific location. Besides, after the driver is selected and the request has been processed by the platform, personal information of the requesting party is sent to the driver, who can either accept or deny the transportation request. In case the sharing partner respectively driver accepts the transportation request, BlaBlaCar executes the booking and sends a confirmation to both parties including the transportation details. Table 1 show a summary of our constructs under study.

\section{Table 1. Summary of key constructs}

\begin{tabular}{|c|c|c|}
\hline Construct & Description & Key reference \\
\hline Trust in platform & $\begin{array}{l}\text { Confidence that the platform will behave in a favorable way, which } \\
\text { makes users comfortable to use the platform and helps them to overcome } \\
\text { perceptions of risk and insecurity. }\end{array}$ & \multirow{2}{*}{$\begin{array}{l}\text { Chen et al. (2009), Kim et } \\
\text { al. (2008), Mittendorf } \\
\text { (2017), Tussyadiah (2015). }\end{array}$} \\
\hline $\begin{array}{l}\text { Trust in sharing } \\
\text { partner }\end{array}$ & $\begin{array}{l}\text { Willingness to rely on favorable future actions of sharing partners to } \\
\text { overcome perceptions of risk and insecurity. }\end{array}$ & \\
\hline Distrust in platform & $\begin{array}{l}\text { Distrust in the platform is the belief that the platform's values or motives } \\
\text { are suspicious. In this regard, users approach the platform in an } \\
\text { objectionable manner, while often having strong negative emotions that } \\
\text { makes them feel insecure and worried. }\end{array}$ & \multirow{2}{*}{$\begin{array}{l}\text { Mcknight and Choudhury } \\
\text { (2006), Schoorman et al. } \\
\text { (2007). }\end{array}$} \\
\hline $\begin{array}{l}\text { Distrust in sharing } \\
\text { partner }\end{array}$ & $\begin{array}{l}\text { Distrust in sharing partners is the belief that the sharing partner's values } \\
\text { or motives are suspicious. In this regard, users approach the sharing } \\
\text { partners in an objectionable manner, while often having strong negative } \\
\text { emotions that makes them feel insecure and worried. }\end{array}$ & \\
\hline Intention to engage & $\begin{array}{l}\text { The intention of using the ridesharing service respectively to engage in a } \\
\text { sharing encounter. }\end{array}$ & $\begin{array}{l}\text { Davis et al. (1989), Gefen et } \\
\text { al. (2003), Mittendorf } \\
\text { (2016), Pavlou (2001). }\end{array}$ \\
\hline
\end{tabular}


The goal of our study is to find out, how trust and distrust regarding the platform and the sharing partner can influence the customers' intention. We base our assumption on existing literature that argues that both trust in the platform and trust in the users can be influential factors $[25,52,55]$. For example, Pavlou and Gefen (2004) argue that a trustworthy intermediary helps to build buyer's trust in a community of sellers, while reducing perceived risk. Furthermore, various researchers, such as Mittendorf (2016, 2017), refer to this finding as providing empirical evidence that the trust-theory can be adopted onto the sharing economy as an influential factor of user intentions.

Accordingly, we assume that trust influences the customers' intentions to perform a respective action on the sharing economy platform under study [45]. In practice, customers have the possibility to engage in a sharing encounter, if they are willing to use the platform, to inquire about available rides, or to request a transportation service. In this regard, Mittendorf (2016, 2017) already demonstrated the relationship between trust and the users' intentions on common sharing economy platforms - such as Airbnb and Uber. However, current findings regarding the influence of trust in sharing partners on user intentions are mixed. Trust in the intermediary seems to always influence the customers intentions, whereas trust in the corresponding sharing partner seems to be only influential in a respective online environment, e.g. with an explicit service duration and financial investment by the customer $[40,41]$.

Given this context of commercial long-distance rides on BlaBlaCar, we hypothesize that the customers' intention to engage in a sharing encounter rises with increased degrees of trust of both the platform and the sharing partners $[6,30]$.

H1. Increased degrees of trust in the platform will increase the customers' intentions to engage in a sharing encounter.

H2. Increased degrees of trust in the sharing partners will increase the customers' intentions to engage in a sharing encounter.

Luhmann (1979) already introduced distrust as an extension and negative functional equivalent of trust. Especially in the sharing economy where interactions with strangers are prevalent, the willingness to take risk respectively to be vulnerable is a common phenomenon [51]. Based on trust theory, McKnight and Chervany (2001) developed separate conceptual models for both trust and distrust suggesting that both constructs do not exclusively perform equal. However, there are few empirical studies that evaluate both trust and distrust as distinct concepts, despite earlier calls by researches, such as Lee and Huynh, (2005), who found that trust and distrust are discriminant and have different outcomes. They further recommend integrating both trust and distrust constructs within the same model to increase explanatory power. Thus, we follow this suggestion and add distrust in the platform and distrust in the sharing partners to our research model. Accordingly our hypotheses are:

H3. Increased degrees of distrust in the platform will decrease the customers' intentions to engage in a sharing encounter.

H4. Increased degrees of distrust in the sharing partners will decrease the customers' intentions to engage in a sharing encounter.

Figure 1. Research model

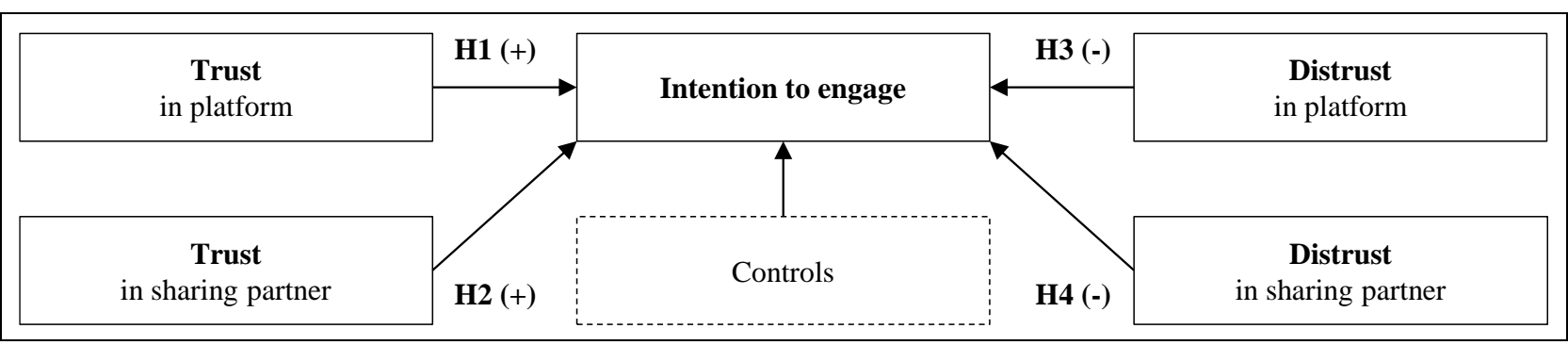

\section{Research method}

\subsection{Instrument development and data collection}

The questionnaire was specifically designed to measure the formation and the implications of trust and distrust on sharing economy platforms from the customers' perspective. Our questionnaire contained 23 questions, covering five constructs, controls, and demographic data. The response format was standardized using a 7-point Likert scale ranging from "strongly disagree" (1) to "strongly agree" (7). Table 7 in the Appendix provides an overview of the final item catalogue, including the constructs, loadings, and the respective item codes. 
The web-based survey was conducted in early 2017. By the due date, we received a total of 238 responses. The data was gathered by targeting participants of countries where our setting - BlaBlaCar - as a method of transportation is available. In more detail, we recruited our participants through suitable social media channels, such as Facebook and Reddit community groups for sharing economy customers. In this regard, we specifically controlled for familiarity respectively experience with sharing economy services. Finally, we dropped 69 participants who did not complete the survey or indicated that they were not honest in answering the survey questions. Table 2 reports the demographic data of the 168 remaining respondents, including gender, age, marital status, education, profession, and income. In this regard, it is necessary to point out that most participants are students; hence, they are young, low-income individuals below the age of 30 years.

Table 2. Sample characteristics

\begin{tabular}{|c|c|c|c|c|c|}
\hline$\underline{N=168}$ & $\underline{\text { Count }}$ & $\underline{\%}$ & & Count & $\%$ \\
\hline $\begin{array}{l}\text { Gender } \\
\text { Female } \\
\text { Male } \\
\text { Age } \\
18 \text { to } 20 \\
21 \text { to } 25 \\
26 \text { to } 30 \\
31 \text { to } 35 \\
36 \text { to } 40 \\
41 \text { to } 45 \\
46 \text { to } 50 \\
51 \text { to } 55 \\
\text { Education } \\
\text { Less than high school } \\
\text { High school graduate } \\
\text { Associate degree } \\
\text { Bachelor's degree } \\
\text { Master's degree }\end{array}$ & $\begin{array}{c}79 \\
89 \\
\\
17 \\
123 \\
15 \\
5 \\
1 \\
1 \\
3 \\
3 \\
\\
1 \\
80 \\
12 \\
60 \\
15\end{array}$ & $\begin{array}{c}47.02 \% \\
52.98 \% \\
\\
10.12 \% \\
73.21 \% \\
8.93 \% \\
2.98 \% \\
0.60 \% \\
0.60 \% \\
1.79 \% \\
1.79 \% \\
\\
0.60 \% \\
47.62 \% \\
7.14 \% \\
35.71 \% \\
8.93 \%\end{array}$ & $\begin{array}{l}\text { Profession } \\
\text { Student } \\
\text { Employed for wages } \\
\text { Self-employed } \\
\text { Yearly income } \\
\text { Less than } \$ 10,000 \\
\$ 10,000 \text { to } \$ 19,999 \\
\$ 20,000 \text { to } \$ 29,999 \\
\$ 30,000 \text { to } \$ 39,999 \\
\$ 40,000 \text { to } \$ 49,999 \\
\$ 50,000 \text { to } \$ 59,999 \\
\$ 60,000 \text { to } \$ 69,999 \\
\$ 70,000 \text { to } \$ 79,999 \\
\$ 80,000 \text { to } \$ 89,999 \\
\$ 90,000 \text { or more } \\
\text { Marital status } \\
\text { Single } \\
\text { Married } \\
\text { Divorced }\end{array}$ & $\begin{array}{c}138 \\
26 \\
4 \\
\\
116 \\
17 \\
11 \\
6 \\
2 \\
4 \\
3 \\
0 \\
1 \\
8 \\
\\
153 \\
8 \\
7\end{array}$ & $\begin{array}{c}82.14 \% \\
15.48 \% \\
2.38 \% \\
\\
69.05 \% \\
10.12 \% \\
6.55 \% \\
3.57 \% \\
1.19 \% \\
2.38 \% \\
1.79 \% \\
0 \\
0.60 \% \\
4.76 \% \\
\\
91.07 \% \\
4.76 \% \\
4.17 \%\end{array}$ \\
\hline
\end{tabular}

\section{Data analysis and results}

\subsection{Measurement model}

We used SPSS and SmartPLS to test the reliability of the measurement model and to perform partial least squares structural equation modeling (PLS-SEM). We assessed the reliability and validity of the constructs. Internal consistency was assessed by following the guidelines from Straub et al. (2004), and Hair et al. (2014). Composite Reliability and Cronbach's alpha and need to be above the threshold of 0.70 in order to indicate sufficient reliability
$[3,16]$. Table 3 indicates that all our construct obtained Composite Reliability and Cronbach's alpha adequate scores above the recommended threshold.

We measured construct validity by evaluating convergent validity [44] and discriminant validity [53]. Convergent validity is considered acceptable when the Average Variance Extracted (AVE) values successfully exceed the threshold of 0.50 for all constructs [16,19]. All our constructs reached the recommended threshold. Hence, the analysis indicates that there is no convergent validity problem in our measurement model.

Table 3. Descriptive statistics and reliability indices for constructs

\begin{tabular}{|l|c|c|c|c|}
\hline Item & Cronbach's Alpha & Composite Reliability & Mean & Standard Deviation \\
\hline TrPl & 0.875 & 0.923 & 4.688 & 1.329 \\
\hline TrSP & 0.923 & 0.951 & 4.544 & 1.353 \\
\hline DisTrPl & 0.825 & 0.885 & 3.123 & 1.441 \\
\hline DisTrSP & 0.828 & 0.895 & 3.300 & 1.479 \\
\hline Int & 0.896 & 0.935 & 4.363 & 1.622 \\
\hline $\begin{array}{l}\text { Note: TrPl = Trust in platform, TrSP = Trust in sharing partner, DisTrPl = Distrust in platform, DisTrSP = Distrust in sharing partner, } \\
\text { Int = Intention to engage. }\end{array}$
\end{tabular}


Discriminant validity is defined as the degree to which measures of different latent variables are unique [44]. According to literature, discriminant validity is considered acceptable when the square roots of the AVE are greater than the correlations between the constructs. Table 4 indicates that there are no outliers and all the square roots of the AVE are greater than all cross-correlations, hence indicating that the variance explained by each construct is much larger than the measurement error variance [46].

Table 4. Convergent and discriminant validity coefficients

\begin{tabular}{|l|c||c|c|c|c|c|}
\hline$\underline{\text { Item }}$ & $\underline{\text { AVE }}$ & $\underline{\text { TrPI }}$ & $\underline{\text { TrSP }}$ & $\underline{\text { DisTrPI }}$ & $\underline{\text { DisTrSP }}$ & $\underline{\text { Int }}$ \\
\hline TrPI & 0.801 & 0.895 & & & & \\
\hline TrSP & 0.866 & 0.716 & 0.930 & & & \\
\hline DisTrPI & 0.725 & -0.424 & -0.278 & 0.852 & & \\
\hline DisTrSP & 0.743 & -0.238 & -0.419 & 0.634 & 0.862 & -0.408 \\
\hline Int & 0.828 & 0.560 & 0.549 & -0.337 & 0.910 \\
\hline $\begin{array}{l}\text { Note: AVE } \\
\text { elements are the correlations among latent constructs. }\end{array}$
\end{tabular}

Multicollinearity: Literature recommends to test for multicollinearity problems in order to identify a potential bias [20]. According to previous literature and as suggested by Hair et al. (2014), we examined potential multicollinearity issues with SPSS collinearity diagnosis techniques using VIF (Variance Inflation Factors) and Tolerance values. The recommend threshold for Tolerance and VIF values state that Tolerance values should be greater than 0.1 and VIF values should be less than 3.0 to accept the premise of no multicollinearity problems for reflective constructs $[21,33]$. The result of our multicollinearity analysis of the dependent variable (intention to engage) testing with the respective independent variables (trust and distrust) is shown in Table 5 and demonstrate that multicollinearity should not be an issue in our dataset.

Table 5. Collinearity statistics

\begin{tabular}{|l|c|c|c|c|}
\hline & $\underline{\text { TrPl }}$ & $\underline{\text { TrSP }}$ & $\underline{\text { DisTrPI }}$ & DisTrSP \\
\hline Tolerance & 0.427 & 0.408 & 0.510 & 0.486 \\
\hline VIF & 2.342 & 2.452 & 1.961 & 2.058 \\
\hline Beta & 0.292 & 0.266 & -0.039 & -0.187 \\
\hline $\begin{array}{l}\text { Note: Dependent variable }=\text { Intention to engage; } \\
\text { Beta }=\text { Standardized Coefficient. }\end{array}$
\end{tabular}

Common Method Bias: As we collected self-reported data from an Internet population at one point in time for our study, common method bias (CMB) could be a potential concern $[49,50]$. To this end, CMB could inflate estimates of structural parameters in a research model and therefore result in inaccurate conclusions $[18,49]$. We carried out an appropriate auxiliary analysis to assess potential CMB issues, as addressing CMB is not an integral part of PLS-SEM [18].

Overall, CMB occurs when a significant amount of covariance shared among variables is attributable to the data collection method. We controlled for CMB, performing the Harman's single factor test. The result of the principal components factor analysis reveals that the first factor does not account for more than $50 \%$ of total variance shared by all items [49]; indicating that $\mathrm{CMB}$ is unlikely a potential bias in our dataset.

\subsection{Structural model assessment}

To answer our research question, we confirmed the factor structure of our dataset with SmartPLS. We assessed the relationship between trust respectively distrust and the users' intentions performing structural equation modeling (SEM) [18]. In our analysis, we controlled for (1) age, (2) income, (3) education, (4) marital status (5) disposition to trust, (6) familiarity, and (7) gender, as source of differing results. After we confirmed the factor structure of our dataset in the confirmatory factor analysis, we performed PLS-SEM to analyze both measurement and structural relationships for our research model [18]. Our PLS analysis confirms that the collected data adequately fits our research model $[14,27]$. The given items share only little residual variance and indicate unidimensionality of the SEM approach $[3,27]$. The results of the SEM are presented in Table 6 and visually summarized in Figure 2.

The results show support for two hypotheses. Trust in the platform affects the users' intention to engage, thus supporting H1. This result is not surprising and confirms the results of fellow researchers, such as Hawlitschek et al. (2016), Mittendorf (2016, 2017). $\mathrm{H} 2$, on the other hand, is not supported indicating that the dependence on the sharing partner does not influence the users' intention to engage. This finding is in line with the work of Hong and Cho (2011) in the B2C e-commerce industry, demonstrating that trust in sellers does not have an effect on purchase intentions since trust in the intermediary is the major driver. Similarly, Mittendorf (2016) found that trust in drivers does not influence the customers' intention to request a ride on the ridesharing platform Uber. 
Figure 2. PLS analysis of the research model showing standardized coefficients

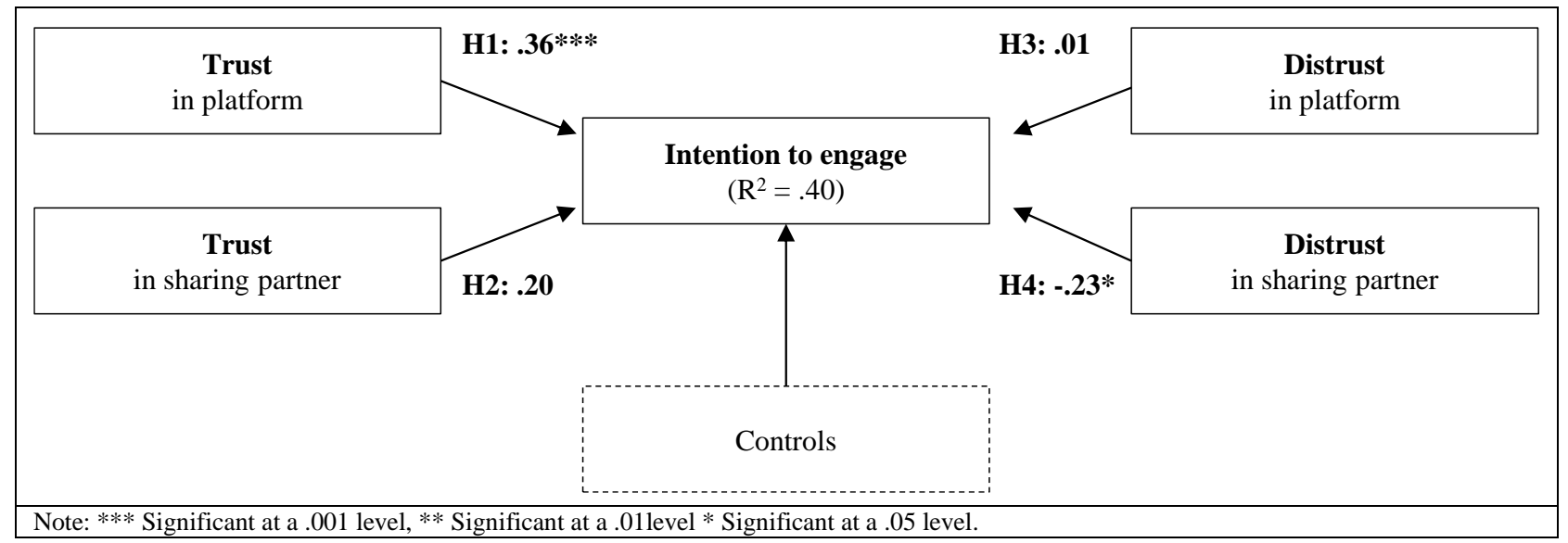

When examining distrust, we find opposing results. Although our analysis shows no significant effect that distrust in the platform influences the users' intention to engage, we find that distrust in the sharing partner has a significant negative effect on the users' intention. Following this logic, the effects of trust and distrust seem to work contrariwise. As an additional robustness check, we evaluated our model with controls and without controls. The results showed no significant difference in both models. Moreover, none of our controls had a statistical significant effect on the dependent variable. Table 6 shows a summary of the study results.

Table 6. Results of hypothesis testing

\begin{tabular}{|c|c|c|c|c|}
\hline Hypothesis & $\underline{\mathbf{S C}}$ & P-Value & CR & Result \\
\hline H1 & $\overline{0.356}$ & **** & $\overline{3.410}$ & $\overline{\text { Supported }}$ \\
\hline $\mathrm{H} 2$ & 0.200 & 0.07 & 1.690 & Not -Supported \\
\hline H3 & 0.008 & 0.94 & 0.081 & Not-Supported \\
\hline $\mathrm{H} 4$ & -0.230 & $*$ & 2.512 & Supported \\
\hline
\end{tabular}

\section{Discussion}

Our research attempts to understand the implications of trust and distrust in the ridesharing industry. In our study, we took the perspective of a potential customer. We analyzed how platform and provider trust respectively distrust influence the users' intentions on the sharing economy platform BlaBlaCar. We intentionally chose BlaBlaCar as a setting as the platform enables a relationship between complete strangers in the online world and allows them to share a ride on short-term notice in the offline world. In order to perform the analysis, we modified the research model from Mittendorf (2017) by separating trust in the intermediary from trust in the sharing partner respectively distrust in the intermediary and distrust in the sharing partner.

\subsection{Research and practical implications}

The data analysis successfully answered our research question. First, we could show that according to McKnight and Choudhury (2006) trust and distrust are two distinct concepts that need to be evaluated separately within one research model. Second, we are in line with Mittendorf (2017) findings, that indicate that trust in the platform is one of the main drivers of users' intentions in the sharing economy (especially within ridesharing services) while trust in the corresponding sharing partner does not affect the users' intentions. Whereas Mittendorf (2017) argues that limited time of interaction or low financial investment with the corresponding sharing partner could be the reasons for finding no effect of trust in the sharing partner on the users' intention, we identified distrust in the sharing partner as the more rigorous driver of users' intentions compared to trust in the sharing partner.

The reason why trust in sharing partners is not an influential factor of the customers' intentions in the sharing economy could have various reasons, which we recommend to examine in future research. For example, it might be hard to judge for potential customers, based on the available information on BlaBlaCar, whether corresponding sharing partners are upright and trustworthy. Thus, as the evaluation of sharing partners itself is limited, the implications of trust respectively missing trust are negligible. Instead, a detailed examination of distrust might be fundamental. With our study, we successfully addressed an existing research gap by analyzing both 
trust and distrust within the sharing economy intermediary framework. Thus, we extend the theoretical background of trust respectively distrust theory while resolving limitations and non-congruent findings that have been frequently formulated by prior researchers [23,40,41]. Overall, our results complement the understanding of the sharing economy with focus on the ridesharing industry.

Based on our theoretical implication, our results offer important insights for managers of sharing economy services. In our study, trust in the platform respectively distrust in the sharing partners appear to be the key drivers of the users' intentions. According to our findings, we make two recommendations to practitioners. First, in order to increase trust in the platform (which might also be of high relevance for the acquisition of new customers respectively the retention of existing customers), we recommend online sharing economy platforms to provide adequate security measures. Those security measures could entail advanced encryption systems for personal information, including location profiles, and demographics in order to guarantee that information will not be misused in any incongruous or unknown way by either the platform or a third party. We further recommend integrating a reliable support system in case of any challenges that might occur when using the platform or to resolve conflicts that might occur with other sharing partners. A collection of those instruments could foster trust in the platform.

Second, in order to decrease distrust in the sharing partners, we recommend the platform to make driver demographics (such as age, gender, nationality) visible and obligatory. In this regard, we also recommend the platform to upfront investigate potential drivers using suitable background checks (such as demanding personal ID information, insurance information, criminal records, and driving license) and point out those background checks within the drivers' profiles. Those instruments in terms of transparent information could be useful in order to decrease distrust and should be investigated in future research.

\subsection{Limitations and future research}

Our study has some limitations. First, we only analyzed a specific sharing economy service in one particular market. Therefore, our study is contextdependent and it is unclear that our findings can be generalized for other sharing service, such as for Uber or Airbnb. Second, our sample mostly represents young, low-income individuals below the age of 30 years; thus, this limits the generalizability for other user groups. Third, we only took the perspective of a potential customer on BlaBlaCar. It might be worthwhile to keep the study design and take the perspective of the corresponding sharing partner. Finally, we only assessed trust as a single construct, thus not evaluating its dimensionality. Therefore, an extended study approach could include the dimensions of trust and distrust.

\section{References}

[1] Andersson, M., Hjalmarsson, A., and Avital, M. Peer-topeer service sharing platforms: Driving share and share alike on a mass-scale. ICIS 2013 Proceedings, (2013), 2964-2978.

[2] Arthursson, D. How Millennials Are Defining the Sharing Economy. Entrepreneur, 2016.

https://www.entrepreneur.com/article/275802.

[3] Bagozzi, R.P. and Yi, Y. On the Evaluation of Structural Equation Models. Journal of the Academy of Marketing Science 16, 1 (1988), 74-94.

[4] Bardhi, F. and Eckhardt, G.M. Access-Based Consumption: The Case of Car Sharing. Journal of Consumer Research 39, (2012), 881-898.

[5] Botsman, R. and Rogers, R. What's Mine Is Yours - How Collaborative Consumption is Changing the Way we live. Collins, 2011.

[6] Chen, J., Zhang, C., and Xu, Y. The Role of Mutual Trust in Building Members' Loyalty to a C2C Platform Provider. International Journal of Electronic Commerce 14, 1 (2009), 147-171.

[7] Cohen, B. and Kietzmann, J. Ride On! Mobility Business Models for the Sharing Economy. Organization \& Environment 27, 3 (2014), 279-296.

[8] Corbitt, B.J., Thanasankit, T., and Yi, H. Trust and ecommerce: A study of consumer perceptions. Electronic Commerce Research and Applications 2, 3 (2003), 203-215.

[9] Cusumano, M.A. How traditional firms must compete in the sharing economy. Communications of the ACM 58, 1 (2014), 32-34.

[10] Davis, F., Bagozzi, R., and Warshaw, P. User acceptance of computer technology: a comparison of two theoretical models. Management science 35, 8 (1989), 9821003.

[11] Deutsch, M., Laboratories, T., and Hill, M. Trust and Suspicion. Journal of Conflict Resolution 2, 4 (1958), 265279.

[12] Eisenmann, T., Parker, G., and Alstyne, M.W. Van. Strategies for Two- Sided Markets. Harvard Business Review 84, 10 (2006), 12.

[13] Ertz, M., Durif, F., and Arcand, M. Collaborative Consumption or the Rise of the Two-Sided Consumer. The 
International Journal Of Business \& Management 4, 6 (2016), 195-209.

[14] Fan, X. and Sivo, S.A. Sensitivity of Fit Indexes to Misspecified Structural or Measurement Model Components: Rationale of Two-Index Strategy Revisited. Structural Equation Modeling: A Multidisciplinary Journal 12, 3 (2005), 343-367.

[15] Faul, F., Erdfelder, E., Lang, A.-G., and Buchner, A. G*Power 3: A flexible statistical power analysis program for the social, behavioral, and biomedical sciences. Behavior Research Methods 39, 2 (2007), 175-91.

[16] Fornell, C. and Larcker, D.F. Evaluating Structural Equation Models with Unobservable Variables and Measurement Error. Journal of Marketing Research 18, 1 (1981), 39-50.

[17] Gefen, D., Karahanna, E., and Straub, D.W. Trust and TAM in Online Shopping: An integrated Model. MIS Quarterly 27, 1 (2003), 51-90.

[18] Gefen, D., Rigdon, E.E., and Straub, D.W. An Update and Extension to SEM Guidelines for Administrative and Social Science Research. MIS Quarterly 35, 2 (2011), iii-xiv.

[19] Gounaris, S. and Dimitriadis, S. Assessing service quality on the Web: evidence from business-to-consumer portals. Journal of Services Marketing 17, (2003), 529-548.

[20] Grewal, R., Cote, J.A., and Baumgartner, H. Multicollinearity and measurement error in structural equation models: Implications for theory testing. Marketing Science 23, 4 (2004), 519-529.

[21] Hair, J.F., Black, W.C.., Babin, B.J., and Anderson, R.E. Multivariate Data Analysis. Pearson, 2014.

[22] Hamari, J., Sjöklint, M., and Ukkonen, A. The Sharing Economy: Why People Participate in Collaborative Consumption. Journal of the Association for Information Science and Technology 67, 9 (2016), 2047-2059.

[23] Hawlitschek, F., Teubner, T., and Weinhardt, C. Trust in the Sharing Economy. Die Unternehmung 70, 1 (2016), 2644.

[24] Hawlitschek, F., Timm, T., Adam, M.T.P., Borchers, N.S., Möhlmann, M., and Weinhardt, C. Trust in the Sharing Economy. ICIS 2016 Proceedings, (2016), 1-15.

[25] Hong, I.B. and Cho, H. The impact of consumer trust on attitudinal loyalty and purchase intentions in B2C emarketplaces: Intermediary trust vs. seller trust. International Journal of Information Management 31, 5 (2011), 469-479.

[26] Hosmer, L.T. Trust: The Connecting Link between Organizational Theory and Philosophical Ethics. The Academy of Management Review 20, 2 (1995), 379-403.

[27] Hu, L. and Bentler, P.M. Cutoff criteria for fit indexes in covariance structure analysis: Conventional criteria versus new alternatives. Structural Equation Modeling: A Multidisciplinary Journal 6, 1 (1999), 1-55.

[28] Jarvenpaa, S.L., Knoll, K., and Leidner, D.E. Is Anybody Out There? Antecedents of Trust in Global Virtual Teams. Journal of Management Information Systems 14, 4 (1998), 29-64.

[29] Jarvenpaa, S.L., Tractinsky, N., and Saarinen, L. Consumer trust in an internet store: a cross culture validation. Journal of Computer Mediated Communication 5, (1999), 135.

[30] Jiang, Q., Huang, X., and Chen, Z. Antecedents and consequences of consumers' trust in electronic intermediaries: An empirical study of hotel booking websites. Frontiers of Business Research in China 3, 4 (2009), 647666.

[31] Kamal, P. and Chen, J.Q. Trust in Sharing Economy. PACIS 2016 Proceedings, (2016), 1-11.

[32] Kim, D.J., Ferrin, D.L., and Rao, H.R. A trust-based consumer decision-making model in electronic commerce: The role of trust, perceived risk, and their antecedents. Decision Support Systems 44, 2 (2008), 544-564.

[33] Kock, N. and Lynn, G.S. Lateral Collinearity and Misleading Results in Variance-Based SEM: An Illustration and Recommendations. Journal of the Association for Information Systems 13, 7 (2012), 546-580.

[34] Lee, J.-N.. B. and Huynh, M.Q.. An integrative model of trust on IT outsourcing: From the service receiver's perspective. 9th Pacific Asia Conference on Information Systems: I.T. and Value Creation, PACIS 2005, (2005), 767779 .

[35] Lewis, D.J., Weigert, A., Lewis, J.D., Weigert, A., and Dame, U.N. Trust as a Social Reality. Oxford University Press 63, 4 (1985), 967-985.

[36] Luhmann, N. Trust and Power. John Wiley \& Sons, 1979.

[37] McKnight, D.H. and Chervany, N.L. What Trust Means in E-Commerce Customer Relationships: An Interdisciplinary Conceptual Typology. International Journal of Electronic Commerce 6, 2 (2001), 35-59.

[38] McKnight, D.H. and Choudhury, V. Distrust and Trust in B2C E-Commerce: Do They Differ? Proceedings of the 8 th international conference on Electronic commerce, (2006), 482-491.

[39] McKnight, D.H., Choudhury, V., and Kacmar, C. The impact of initial consumer trust on intentions to transact with web site: A trust building model. Journal of Strategic Information Systems 11, (2002), 297-323.

[40] Mittendorf, C. What Trust means in the Sharing Economy: A provider perspective on Airbnb.com. AMCIS 2016, (2016), 1-10. 
[41] Mittendorf, C. The Implications of Trust in the Sharing Economy - An Empirical Analysis of Uber. HICSS 2017 Proceedings, (2017), 5837-5846.

[42] Möhlmann, M. Collaborative consumption: determinants of satisfaction and the likelihood of using a sharing economy option again. Journal of Consumer Behaviour 14, 3 (2015), 193-207.

[43] Morgan, R.M. and Hunt, S.D. The Commitment-Trust Theory of Relationship Marketing. Journal of Marketing 58, 3 (1994), 20-38.

[44] O'Leary-Kelly, S.W. and Vokurka, R.J. The empirical assessment of construct validity. Journal of Operations Management 16, 4 (1998), 387-405.

[45] Pavlou, P.A. Integrating Trust in Electronic Commerce with the Technology Acceptance Model: Model Development and Validation. AMCIS 2001 Proceedings, (2001), 816-822.

[46] Pavlou, P.A. and Dimoka, A. The nature and role of feedback text comments in online marketplaces: Implications for trust building, price premiums and seller differentiation. Information Systems Research 17, 4 (2006), 392-414.

[47] Pavlou, P.A. and Gefen, D. Building Effective Online Marketplaces with Institution-Based Trust. ICIS 15, 1 (2002), 667-675.

[48] Pavlou, P.A. and Gefen, D. Building effective online marketplaces with institution-based trust. Information Systems Research 15, 1 (2004).

[49] Podsakoff, P.M., MacKenzie, S.B., Lee, J.-Y., and Podsakoff, N.P. Common method biases in behavioral research: a critical review of the literature and recommended remedies. The Journal of applied psychology 88, 5 (2003), 879-903.

[50] Podsakoff, P.M. and Organ, D.W. Self-Reports in Organizational Research: Problems and Prospects. Journal of Management 12, 4 (1986), 531-544.
[51] Schoorman, F.D., Mayer, R.C., and Davis, J.H. An integrative model of organizational trust: Past, present, and future. Academy of Management Review 32, 2 (2007), 344354.

[52] Son, J. and Benbasat, I. Trust-building Measures In B2b Electronic Marketplaces. Communications of AIS 18, (2006), $2-52$.

[53] Straub, D., Boudreau, M.-C., and Gefen, D. Validation Guidelines for Is Positivist Research. Communications of the Association for Information Systems 13, (2004), 380-427.

[54] Tussyadiah, I.P. An Exploratory Study on Drivers and Deterrents of Collaborative Consumption in Travel. Information \& Communication Technologies in Tourism 2015 Proceedings, (2015), 817-830.

[55] Verhagen, T., Meents, S., and Tan, Y.-H. Perceived risk and trust associated with purchasing at electronic marketplaces. European Journal of Information Systems 15, 6 (2006), 542-555.

[56] Wang, Y.D. and Emurian, H.H. An overview of online trust: Concepts, elements, and implications. Computers in Human Behavior 21, 1 (2005), 105-125.

[57] Weber, T.A. Intermediation in a Sharing Economy: Insurance, Moral Hazard, and Rent Extraction. Journal of Management Information Systems 31, 3 (2014), 35-71.

[58] Zervas, G., Proserpio, D., and John, B. The Rise of the Sharing Economy: Estimating the Impact of Airbnb on the Hotel Industry. Journal of Marketing Research, (2017), 136.

[59] Zheng, H., Li, D., and Hou, W. Task Design, Motivation, and Participation in Crowdsourcing Contests. International Journal of Electronic Commerce 15, 4 (2011), $57-88$.

Table 7. Overview of items after the content validity assessment

\begin{tabular}{|l|l|c|l|}
\hline Construct & Code & Loading & Item \\
\hline \multirow{2}{*}{$\begin{array}{l}\text { Trust in } \\
\text { platform }\end{array}$} & TrP11 & 0.904 & I feel that BlaBlaCar is honest. \\
\cline { 2 - 4 } & TrP12 & 0.949 & I feel that BlaBlaCar is trustworthy. \\
\cline { 2 - 4 } $\begin{array}{l}\text { Trust in sharing } \\
\text { partner }\end{array}$ & TrP13 & 0.828 & I feel BlaBlaCar is reliable. \\
\cline { 2 - 4 } & TrSP1 & 0.948 & I feel that the drivers on BlaBlaCar are honest. \\
\cline { 2 - 4 } & TrSP3 & 0.967 & I feel that the drivers on BlaBlaCar are trustworthy. \\
\hline \multirow{2}{*}{$\begin{array}{l}\text { Distrust in } \\
\text { platform }\end{array}$} & DisTrP11 & 0.874 & I feel the drivers on BlaBlaCar are reliable. \\
\cline { 2 - 4 } & DisTrP12 & 0.946 & Overall, I worry about whether BlaBlaCar is reliable. \\
\cline { 2 - 4 } $\begin{array}{l}\text { Distrust in } \\
\text { sharing partner }\end{array}$ & DisTrP13 & 0.938 & I feel nervous about the service BlaBlaCar provides. \\
\cline { 2 - 4 } $\begin{array}{l}\text { Intention to } \\
\text { engage }\end{array}$ & DisTrSP1 & 0.724 & Overall, I worry about whether drivers on BlaBlaCar are reliable. \\
\cline { 2 - 4 } & DisTrSP2 & 0.908 & I feel nervous about the services drivers on BlaBlaCar provide. \\
\cline { 2 - 4 } & Inq1 & 0.939 & I would feel cautious about characterizing drivers on BlaBlaCar as honest. \\
\cline { 2 - 4 } & Inq2 & 0.908 & I would feel comfortable requesting a ride on BlaBlaCar. \\
\cline { 2 - 4 } & Inq3 & 0.921 & I am very likely to request a ride on BlaBlaCar. \\
\hline \multirow{2}{*}{} & 0.900 & I would engage in a sharing encounter on BlaBlaCar in general. \\
\hline
\end{tabular}

